charge. At the higher rates of cleavage which they used, moreover, such behaviour may be more likely than if the cleavage occurs as a nearly equilibrium process. (This point has been brought out by Miss Bailey ${ }^{7}$.) The present experiments, of course, cannot distinguish between a uniform distribution of potassium ions and an array of small patches, and therefore I am not able to evaluate the importance of this contribution.

I am greatly indebted to Miss C. P. Rutkowski for experimental assistance and to Dr. David Tabor for interesting discussions.

George L. Gatnes, Jun.

General Electric Research Laboratory, Schenectady, New York. Feb. 9.

1 Bailey, A. I., Proc. Second Int. Congress of Surface Activity, III, 406 (Butterworths, London, 1957).

${ }^{2}$ Gaines, jun., G. L., and Tabor, D., Nature, 178, 1304 (1956).

${ }^{3}$ Gaines, jun., G. L., J. Phys. Chem., 61, 1408 (1957).

${ }^{4}$ Rideal, E., and Tadayon, J., Proc. Roy. Soc., A, 225, 346 (1954).

${ }^{5}$ Bailey, A. I., and Courtney-Pratt, J. S., Proc. Roy. Soc., A, 227, 500 (1955) ${ }^{6}$ Derjaguin, B. V., Krotova, N. A., and Karasev, V. V., Doklady 1,466 . Derjaguin, B.' V., et al., ref. 1, p. 417.

Bailey, A. Y., ref. 1, p. 445 .

\section{Material Transfer in Monomolecular Layers of a Boundary Lubricant}

Bailey and Courtney-Pratt ${ }^{1}$ have studied the shearing of monomolecular layers of calcium stearate between flat mica sheets. They concluded that this shearing in the boundary lubricant film, which may afford almost perfect protection against wear, stil contributes significantly to sliding friction. The processes which occur in the contact of such atomically flat surfaces protected by boundary films are therefore of some interest. It has been shown that mica surfaces brought into contact interchange the exchangeable potassium ions on their surfaces (preceding communication). This observation seems to support the postulate that the adhesive force between mica surfaces is ionic in nature ${ }^{2}$. Rideal and Tadayon ${ }^{3}$ observed transfer of stearic acid from monolayers deposited on mica to other mica surfaces, but the major portion of their work seems to have been concerned with surface diffusion processes rather than true contact transfer.

In this communication the results of some preliminary measurements of area of true contact and transfer of stearic acid from monolayers, as well as migration of surface potassium ions through such monolayers are reported. The methods of Bailey and Courtney-Pratt ${ }^{1}$ were used to measure contact areas and the potassium ion transfer was detected with potassium -42 , as in the previous communication. Potassium ion migration was observed from an ionexchanged mica surface to a sheet of mica coated with a monolayer of commercially pure stearic acid (Armour 'Neo-Fat 18'). Stearic acid transfer was observed by measuring the activity transferred from a mica surface coated with a monolayer of stearic acid labelled with carbon-14 at the carboxyl group to an untreated surface. In both types of experiments, monolayer deposition was accomplished by the Blodgett technique ${ }^{5}$, using a distilled water substrate and a surface pressure of about 30 dynes $/ \mathrm{cm}$. (oleic acid piston oil). The stearic acid was spread from hexane solution. The results of the transfer measurements are recorded in Table 1 .
Table 1. TRANSTER OF POTASSIOM-42 AND STEARIC ACID-14 $\mathrm{COOH}$ A. Potassium ion transfer in the presence of a stearic acid film

\begin{tabular}{|c|c|c|c|c|}
\hline & $\begin{array}{c}\text { Potassium }-42 \\
\text { exchanged } \\
\text { sheet, observed } \\
\left(\mathrm{c} . / \mathrm{min} . / \mathrm{cm} .^{2}\right)^{*}\end{array}$ & $\begin{array}{l}\text { Contact } \\
\text { area } \\
\left(\mathrm{cm} .{ }^{2}\right)\end{array}$ & $\begin{array}{c}\text { Contacted } \\
\text { sheet } \\
\text { (c./min.) obs.* }\end{array}$ & $\begin{array}{c}\text { Transferred } \\
\text { activity } \\
\text { (c./min./cm. }{ }^{2} \text { ) }\end{array}$ \\
\hline $\begin{array}{l}1 \\
2 \\
3\end{array}$ & $\begin{array}{r}290(10) \\
1,100(15) \\
900(10)\end{array}$ & $\begin{array}{l}0 \cdot 052 \\
0.092 \\
0.002\end{array}$ & $\begin{array}{r}11.2(2.8) \\
20.6(1.8) \\
1.7(1.6)\end{array}$ & $\begin{array}{l}214 \\
224 \\
850\end{array}$ \\
\hline
\end{tabular}

(Samples 2 and 3 from a different lot of potassium-42 than sample 1.) $B$. Stearic acid-14 $\mathrm{COOH}$ transfer.

\begin{tabular}{|c|c|c|c|c|}
\hline & $\begin{array}{c}\text { Monolayer- } \\
\text { coated sheet, } \\
\text { observed } \\
\text { (c./min./cm. }{ }^{2} \text { ) } t\end{array}$ & $\begin{array}{l}\text { Contact } \\
\text { area } \\
\left(\mathrm{cm}^{2}\right)\end{array}$ & $\begin{array}{c}\text { Contacted } \\
\text { sheet } \\
\text { (c./min.) obs.* }\end{array}$ & $\begin{array}{l}\text { Transferred } \\
\text { activity } \\
\text { (c./min./cm. }{ }^{2} \text { ) }\end{array}$ \\
\hline $\begin{array}{l}1 \\
2 \\
3 \\
4\end{array}$ & $\begin{array}{c}313(3 \cdot 0) \\
\square \\
\square\end{array}$ & $\begin{array}{l}0 \cdot 093 \\
0 \cdot 0051 \\
0 \cdot 016 \\
0 \cdot 018\end{array}$ & $\begin{array}{l}6 \cdot 2(0 \cdot 5) \\
1 \cdot 5(1 \cdot 1) \\
1 \cdot 1(1 \cdot 0) \\
2 \cdot 0(1 \cdot 1)\end{array}$ & $\begin{array}{r}67 \\
294 \\
68 \\
111\end{array}$ \\
\hline
\end{tabular}

* Counting standard deviations in parentheses. All counting-rates corrected for background, counter resolving-time and decay, where appropriate.

i Samples 1-3 were all coated from the same spread monolayer. ample 4 was a separate monolayer spread from the same solution.

It is apparent from Table 1 that these results obtained are very crude and must be considered as preliminary. It is, however, clear that some transfer of both stearic acid and potassium ion does occur. Whether transfer of potassium ions occurs here through formation of a soap and migration of the entire soap molecule cannot be decided on the basis of the present results-radioactivity measurements of higher precision (which would require reagents of higher specific activity than were at hand in this work) would be needed to decide this point. The interesting differences in diffusion transfer of monolayers observed by Rideal and Tadayon make this point of some interest in connexion with the processes occurring in boundary lubricant layers. The ability of molecules to move from monolayers on one member of a sliding couple to the other member will be important in the protection of the surfaces, and the possibility of transferring metallic ions either through the monolayer or in conjunction with overturning lubricant molecules must be recognized.

I am indebted to Miss C. P. Rutkowski for assistance with these experiments.

\section{General Electric Research Laboratory,} Schenectady, New York. Feb. 9.

${ }^{1}$ Bailey, A. I., and Courtney-Pratt, J. S., Proc. Roy. Soc., A, 227, 500 (1955)

${ }^{2}$ Gaines, jun., G. L., and Tabor, D., Nature, 178, 1304 (1956).

${ }^{3}$ Rideal, E., and Tadayon, J., Proc. Roy. Soc., A, 225, 346 (1954).

${ }^{4}$ Gaines, jun., G. L., J. Phys. Chem., 61, 1408 (1957).

${ }^{5}$ Blodgett, K. B., J. Amer. Chem. Soc., 57, 1007 (1935).

\section{A New Method of Integration Recording}

The method now commonly used for recording continuously and in real time the integral of an instrument output signal requires the counting of pips in the final record. It is therefore essentially digital in nature. We have devised in our laboratory an analogue method (patents applied for) that eliminates counting and produces a new form of record, an 'integram', that appears to be particularly interesting and useful for gas chromatography.

The general scheme of the method is shown in Fig. 1. A conventional pen servo responsive to the signal drives the pen across the chart in the usual 